\title{
Deuterium Retention in Toughed, Fine-grained Recrystallized Tungsten
}

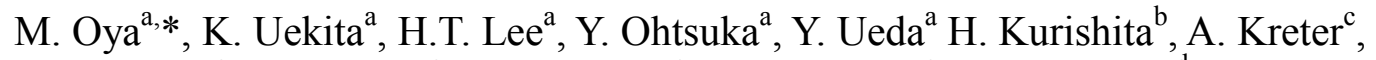 \\ J. W. Coenen ${ }^{\mathrm{c}}$, V. Philipps ${ }^{\mathrm{c}}$, S. Brezinsek ${ }^{\mathrm{c}}$, A. Litnovsky ${ }^{\mathrm{c}}$, K. Sugiyama ${ }^{\mathrm{d}}$, Y. Torikai ${ }^{\mathrm{e}}$ \\ ${ }^{a}$ Graduate School of Engineering, Osaka University, Suita, Osaka, 565-0871, Japan \\ ${ }^{a}$ Institute for Materials Research, Tohoku University, Oarai, Ibaraki 311-1313, Japan \\ ${ }^{c}$ Institute for Energy and Climate Research, Forschungszentrum Jülich, Association EURATOM-FZJ, \\ Trilateral Euregio Cluster, 52425 Jülich Germany \\ ${ }^{d}$ Max-Planck-Institut für Plasmaphysik, EURATOM Association, D-85748 Garching, Germany \\ ${ }^{e}$ Hydrogen Isotope Research Center, University of Toyama, Gofuku 3190, Toyama 930-8555, Japan
}

\begin{abstract}
Deuterium retention in Toughened, Fine-Grained Recrystallized W (TFGR W 1.1TiC) was studied, compared to pure W. D implantation was performed to a fluence of $1 \times 10^{24} \mathrm{~m}^{-2}$ at temperatures of $473-873 \mathrm{~K}$ followed by TDS. It was found that D retention in TFGR W is higher than pure $\mathrm{W}$ at all irradiation temperatures. Namely, at $673 \mathrm{~K}$, D retention in TFGR W is six times higher than pure $\mathrm{W}$. TDS spectrum of TFGR $\mathrm{W}$ irradiated at $573 \mathrm{~K}$ has a large peak around $\sim 700 \mathrm{~K}$ with small shoulder up to $\sim 1100 \mathrm{~K}$. In the case of D + He simultaneous irradiation, D retention is about $30 \%$ lower than for pure D. In addition, plasma exposure experiment was also conducted in TEXTOR, followed by NRA. Higher retention in TFGR $\mathrm{W}-1.1 \mathrm{wt} \% \mathrm{TiC}$ could be attributed to high grain boundary diffusion (then trapping deeper into the bulk) and formation of $\mathrm{TiD}_{2}$.
\end{abstract}

PACS: $52.40 . \mathrm{Hf}, 52.55 . \mathrm{Rk}$

PSI-20 Keywords: Deuterium retention, Divertor material, Ion implantation, Tungsten,

*Corresponding author address: Graduate School of Engineering, AR-G2-301, Osaka University, 2-1 Yamadaoka, Suita, Osaka, 565-0871, Japan

*Corresponding author email: ohya@st.eie.eng.osaka-u.ac.jp

Presenting author: M. Oya

Presenting author email: ohya@st.eie.eng.osaka-u.ac.jp 


\section{Introduction}

Tungsten (W) will be used as a plasma-facing material (PFM) in future fusion reactor and in the divertor of ITER. However, W suffers from poor mechanical properties such as high ductile to brittle transition temperature resulting in room temperature brittleness or neutron irradiation embrittlement [1].

In order to improve the mechanical property, a variety of advanced tungsten materials are being researched and developed. One such W material is Toughened, Fine-Grained Recrystallized Tungsten (TFGR-W) developed at Tohoku University [2]. During the manufacturing process, small amounts of titanium carbide (TiC) are added for grain boundary strengthening. TFGR $\mathrm{W}$ has shown improved room temperature ductility and resistance against neutron embrittlement compared to pure $\mathrm{W}$ materials [2, 3]. However, if TFGR W will be used as PFMs, its hydrogen retention properties must be known due to safety concerns related to tritium.

At present, the hydrogen retention properties of TFGR $\mathrm{W}-1.1 \mathrm{wt} \% \mathrm{TiC}$ are not well known. Specifically, there is a concern of increased retention due to the presence of Ti and C which can act as an additional trapping site. An earlier study has shown reduced (D) retention in TFGR W-1.1 wt\% $\mathrm{TiC}$ exposed to D plasma at $573 \mathrm{~K}$ in comparison to pure $\mathrm{W}$ [4]. In this study, we investigated $\mathrm{D}$ retention in TFGR $\mathrm{W}-1.1 \mathrm{wt} \% \mathrm{TiC}$ by ion beam implantation followed by thermal desorption, and by plasma exposure in the TEXTOR tokamak followed by nuclear reaction analysis made in IPP Garching. These experiments aimed to increase the D retention database of TFGR $\mathrm{W}-1.1 \mathrm{wt} \% \mathrm{TiC}$ and clarify $\mathrm{D}$ retention mechanisms.

\section{Experimental}

Two types of W samples were investigated: (1) pure W, and (2) TFGR W-1.1wt\%TiC. Sample dimensions were $10 \times 10 \times 1 \mathrm{~mm}^{3}$. Pure W sample was fabricated by A.L.M.T. Corp., 
Japan. TFGR W-1.1wt\%TiC samples were fabricated, at Tohoku University by mechanical alloying, hot isostatic pressing and plastic working. Further details of the sample fabrication are found in Ref. [2]. All Samples were annealed at $1573 \mathrm{~K}$ for $1 \mathrm{~h}$ in vacuum after mechanically polishing. The average grain size of TFGR $\mathrm{W} \sim 1 \mu \mathrm{m}$ with TiC dispersoids located at grain boundaries.

Deuterium and helium (5\%) mixed ion implantation was performed using the HiFIT device at Osaka University [5]. The ion flux was $\sim 1 \times 10^{20} \mathrm{D} \mathrm{m}^{-2} \mathrm{~s}^{-1}$ with implantation fluence was $1 \times 10^{24} \mathrm{D} \mathrm{m}^{-2}$. The ion energy was $1 \mathrm{keV}$. The sample was heated oppositely from the irradiation side by using an infrared heater. Temperature was measured by a thermocouple (type K) attached at the front surface of samples and was controlled by using feedback loop with the thermocouple and a heating circuit.

Following implantation, thermal desorption spectroscopy (TDS) was performed in a separate system. The ramping rate was $0.1 \mathrm{~K} / \mathrm{s}$ up to a maximum sample temperature of 1273 K. The TDS spectra was collected using a quadrupole mass spectrometer (QMS, MKS Microvision 2). Typical base pressure was $\sim 6 \times 10^{-7} \mathrm{~Pa}$. D retention was determined by the sum of $\mathrm{HD}$ (mass3) and $\mathrm{D}_{2}$ (mass4) signals. The QMS signals were calibrated using a standard $\mathrm{D}_{2}$ calibration leak and the QMS sensitivity to HD was assumed to be the average of $\mathrm{H}_{2}$ and $\mathrm{D}_{2}$. All TDS spectra for $\mathrm{D}$ atoms shown in this paper are the sum of HD and $\mathrm{D}_{2}$ signals. Total D retention was determined by integrating the TDS spectra.

To investigate D retention in TFGR W under tokamak conditions, pure W and TFGR W-1.1wt\%TiC samples were simultaneously exposed side by side in TEXTOR using a graphite roof limiter, shown in Fig.1. The D ohmic plasma conditions were as follows: $B_{\mathrm{t}}=$ 2.25 T, $I_{\mathrm{p}}=350 \mathrm{kA}, n_{\mathrm{e}}=2.5 \times 10^{19} \mathrm{~m}^{-3}$. The samples were exposed 21 identical ohmic shots. Flux to the samples was between $10^{21}$ and $10^{22} \mathrm{~m}^{-2} \mathrm{~s}^{-1}$ and $\mathrm{D}$ ion bombarding energy was estimated to $160 \mathrm{eV}$ [6]. Surface temperature of the samples was roughly $600 \mathrm{~K}$ during 
plasma exposure (increase by about $30 \mathrm{~K}$ during exposure). After TEXTOR edge plasma exposure, no carbon deposition was observed. Following the D exposure, depth profiling of the retained $\mathrm{D}$ was done by Nuclear Reaction Analysis (NRA) using the $\mathrm{D}\left({ }^{3} \mathrm{He}, \mathrm{p}\right)^{4} \mathrm{He}$ reaction and varying the incident ${ }^{3} \mathrm{He}$ energies from 0.69 to $4 \mathrm{MeV}$.

\section{Results}

Fig. 2 (a) shows the D thermal desorption spectra from pure $\mathrm{W}$ and TFGR W$1.1 \mathrm{wt} \% \mathrm{TiC}$ at various temperatures. At $573 \mathrm{~K}$ irradiation, one broad desorption peak at $\sim 700$ K was observed for pure $\mathrm{W}$, see curve (1). For TFGR W-1.1wt $\%$ TiC, the desorption peak at $700 \mathrm{~K}$ was also observed but was approximately ten times larger, see curve (2). Also, a long tail (shoulder) extending to $1200 \mathrm{~K}$ was observed. This coincides with desorption peaks at $900 \mathrm{~K}$ and $1000 \mathrm{~K}$ for irradiation at (3) $773 \mathrm{~K}$ and (4) $873 \mathrm{~K}$, respectively. On the other hand, higher temperature peaks are not observed for pure $\mathrm{W}$ for irradiation at $\mathrm{T}>773 \mathrm{~K}[7,8]$.

Fig.2 (b) shows the D thermal desorption spectra from TFGR W-1.1wt\%TiC, which was irradiated using a mixed D + He beam at $473 \mathrm{~K}$. For comparison, spectra from D-only beam at $573 \mathrm{~K}$ is shown. Although the irradiation temperatures were different, obvious reduction of low temperature peak in the spectra can be seen. The high temperature peak remains and shows almost no change in the height compared to D-only irradiation.

Fig.3 shows NRA depth profiling of D retained in pure $\mathrm{W}$ and TFGR $\mathrm{W}-1.1 \mathrm{wt} \% \mathrm{TiC}$. In pure $\mathrm{W}$, most of $\mathrm{D}$ atoms were trapped within the near surface layer up to $\sim 0.1 \mu \mathrm{m}$ in depth, followed by a sharp decrease with increasing depth. At a depth $>1 \mu \mathrm{m}$, the D concentration was below the detection limit of $10^{-3}$ at.\%. In contrast, D concentration in TFGR $\mathrm{W}-1.1 \mathrm{wt} \% \mathrm{TiC}$ was higher than pure $\mathrm{W}$ at all measured depth range of $0 \sim 6 \mu \mathrm{m}$. Specifically, at depths $>1 \mu \mathrm{m}, \mathrm{D}$ concentration was much higher with almost constant value $4 \times 10^{-3}$ at.\%. The total amount of $\mathrm{D}$ retention within the depth probed was an order of 
magnitude higher in TFGR W-1.1wt\% TiC in comparison to pure W. $\left(2.2 \times 10^{20} \mathrm{D} \mathrm{m}^{-2}\right.$ and 3.3 $\times 10^{19} \mathrm{D} \mathrm{m}^{-2}$, respectively)

Fig.4 shows the total amount of $\mathrm{D}$ retention in pure $\mathrm{W}$ and TFGR $\mathrm{W}-1.1 \mathrm{wt} \% \mathrm{TiC}$, calculated from thermal desorption spectrum. At $473 \mathrm{~K}$ irradiation, the total retention between TFGR W-1.1wt\% TiC is comparable to pure W. However, at T $>473 \mathrm{~K}$, D retention in TFGR $\mathrm{W}-1.1 \mathrm{wt} \% \mathrm{TiC}$ is higher than pure W. Specifically, at $573 \mathrm{~K}$, the difference is one order of magnitude $\left(2.2 \times 10^{21} \mathrm{D} \mathrm{m}^{-2}\right.$ and $1.6 \times 10^{20} \mathrm{~m}^{-2}$, respectively). At $673 \mathrm{~K}$, the retained amount of D decreases but still TFGR W-1.1wt\%TiC is higher than pure $\mathrm{W}\left(5.1 \times 10^{20} \mathrm{D} \mathrm{m}^{-2}\right.$. and 8.0 $\times 10^{20} \mathrm{D} \mathrm{m}^{-2}$, respectively). D retention in TFGR W-1.1wt\%TiC decreases more slowly than pure $\mathrm{W}$ with increasing irradiation temperature.

Fig. 4 also shows D retention within $6 \mu \mathrm{m}$ from NRA results, in which $\mathrm{W}$ samples were irradiated at around $600 \mathrm{~K}$ in TEXTOR. Again the amount of D retention in TFGR W$1.1 \mathrm{wt} \% \mathrm{TiC}$ was higher than in pure $\mathrm{W}$. These results are consistent with the $\mathrm{D}$ retention behaviour observed from ion beam experiments, although the experimental conditions are different (fluxes and ion energy).

In the case of $\mathrm{D}+\mathrm{He}$ implantation, $\mathrm{D}$ retention in TFGR $\mathrm{W}-1.1 \mathrm{wt} \% \mathrm{TiC}$ was lower by $\sim 70 \%$ in comparison to D-only case at $473 \mathrm{~K}$. This is consistent with the observation that mixed He implantation decreases D retention as observed in pure W [4]. Evidently, the He effect also holds for TFGR W-1.1wt\% TiC.

\section{Discussion}

A clear increase in $\mathrm{D}$ retention in TFGR $\mathrm{W}-1.1 \mathrm{wt} \% \mathrm{TiC}$ compared to pure $\mathrm{W}$ has been observed. The increased retention could be due to: (1) smaller grain sizes resulting in higher grain boundary densities, or (2) TiC dispersoids acting as additional trapping sites. 
If additional grain boundary density is responsible for increased retention, this may be due to increased diffusion along grain boundaries resulting in deeper penetration into the bulk. This is supported by the study where increased retention in W was observed with decreasing grain size. $[9,10]$ Most of diffusing D atoms may be trapped at trap site with low energy. The trap site could be dislocation, according to Ref. [11].

As seen by the high temperature desorption peak, TFGR W-1.1wt\% TiC has the trap site with higher energy, which does not exist in pure W. The trap site could be TiC dispersoids. One possible explanation is the chemical bonding of $\mathrm{Ti}$ with $\mathrm{D}$ atoms form $\mathrm{TiD}_{2}$. It is known that, most of $\mathrm{TiD}_{2}$ decomposes at $900 \sim 1000 \mathrm{~K}$ [12]. This is consistent with the observed high temperature peak range from TDS. D retention in TFGR $\mathrm{W}-1.1 \mathrm{wt} \% \mathrm{TiC}$ was still high at high irradiation temperatures, at which $\mathrm{D}$ retention in pure $\mathrm{W}$ was significantly lower. This is likely related to the high trapping energy of $\mathrm{TiC}$ becoming dominant at high temperatures.

In case of $\mathrm{D}+\mathrm{He}$ implantation, reduction of $\mathrm{D}$ retention in TFGR $\mathrm{W}-1.1 \mathrm{wt} \% \mathrm{TiC}$ can be seen, as was also seen and explained in previous papers in pure $\mathrm{W}[4,13]$. This reduction could be due to instant release of $\mathrm{D}$ molecules along surface-connected pores produced by coalescence of He bubbles [14]. Therefore, D atom diffusion into inner part of W was suppressed.

Results that D retention in TFGR $\mathrm{W}-1.1 \mathrm{wt} \% \mathrm{TiC}$ is high are opposite to previous research in PISCES-A [4]. In this research, D retention in TFGR W-1.1wt\%TiC was drastically lower than in pure W. This difference may be related to different experimental conditions (flux, energy and etc.), therefore more research on D behaviour in TFGR W should be done under various conditions.

\section{Conclusion}


$\mathrm{D}$ retention in TFGR $\mathrm{W}-1.1 \mathrm{wt} \% \mathrm{TiC}$ was systematically higher than in pure $\mathrm{W}$ at all irradiation temperatures. This may be due to increased trapping at grain boundaries or TiC dispersoids. Long diffusion tail supports increased diffusion into bulk due to grain boundary diffusion as seen by NRA depth profile.

Desorption peaks at higher temperatures were observed in TDS spectra in TFGR W$1.1 \mathrm{wt} \% \mathrm{TiC}$ which are normally not observed in pure $\mathrm{W}$. This indicates that the increased retention is partially due to trapping at trap sites with higher binding energies. It is postulated that the origin of this high temperature desorption peak is due to $\mathrm{D}$ trapped at TiC dispersoids. These higher energy trap sites are likely responsible for the high retention observed in TFGR $\mathrm{W}-1.1 \mathrm{wt} \% \mathrm{TiC}$ even at high irradiation temperature. In case of $\mathrm{D}+\mathrm{He}$ implantation, reduction in $\mathrm{D}$ retention was observed consistent with pure $\mathrm{W}$ materials. 


\section{References}

[1] V. Philipps 2011 J. Nucl. Mater. 415 S2-S9.

[2] H. Kurishita et al 2010 J. Nucl. Mater. 398 87-92.

[3] H. Kurishita et al 2008 J. Nucl. Mater. 377 34-40.

[4] M. Miyamoto et al 2008 Nucl.Fusion. 49065035.

[5] T. Shimada et al 2002 Rev. Sci. Instrum. 731741.

[6] Y. Ueda et al $2011 \mathrm{~J}$. Nucl. Mater. 415 S92-S95.

[7] G.-N. Luo et al 2009 Nucl. Inst. Methods B 267 3041-3045.

[8] V.Kh. Alimov et al 2011 J. Nucl. Mater. 417 572-575.

[9] W.M. Shu et al 2009 J. Nucl. Mater. 386-388 356-359.

[10] D.A. Komarov et al 2001 J. Nucl. Mater. 290-293 433-436.

[11] O.V. Ogorodnikova, J. Roth, and M. Mayer 2008 J. Appl. Phys. 103034902

[13] V.Kh. Alimov et al 2012 J. Nucl. Mater. 420 370-373.

[14] V.Kh. Alimov et al 2009 Phys. Scr. T138 014048. 


\section{Figure Captions}

Figure 1: pure $\mathrm{W}$ and TFGR W-1.1wt\% TiC samples were simultaneously exposed side by side in TEXTOR using the graphite roof limiter. The D ohmic plasma conditions were as follows: $B_{\mathrm{t}}=2.25 \mathrm{~T}$, $I_{\mathrm{p}}=350 \mathrm{kA}, n_{\mathrm{e}}=2.5 \times 10^{19} \mathrm{~m}^{-3}$.

Figure 2: Thermal desorption spectra of: (a) D release from pure W and TFGR W-1.1wt\%TiC. Irradiation temperature was $573 \mathrm{~K}, 773 \mathrm{~K}$ and $873 \mathrm{~K}$. The TDS ramping rate was $0.1 \mathrm{~K} / \mathrm{s}$ and (b) D release from TFGR $\mathrm{W}-1.1 \mathrm{wt} \%$ TiC with D-only implantation at $573 \mathrm{~K}$ and $\mathrm{D}+\mathrm{He}(5 \%)$ implantation at $473 \mathrm{~K}$

Figure 3: Deuterium depth profile in pure $\mathrm{W}$ and TFGR W-1.1wt\% TiC exposed to D plasma at TEXTOR

Figure 4: $\mathrm{D}$ retention in $\mathrm{W}$ samples as function of irradiation temperature. The total $\mathrm{D}$ retention was measured by thermal desorption spectroscopy (TDS). 
Figure 1: one column

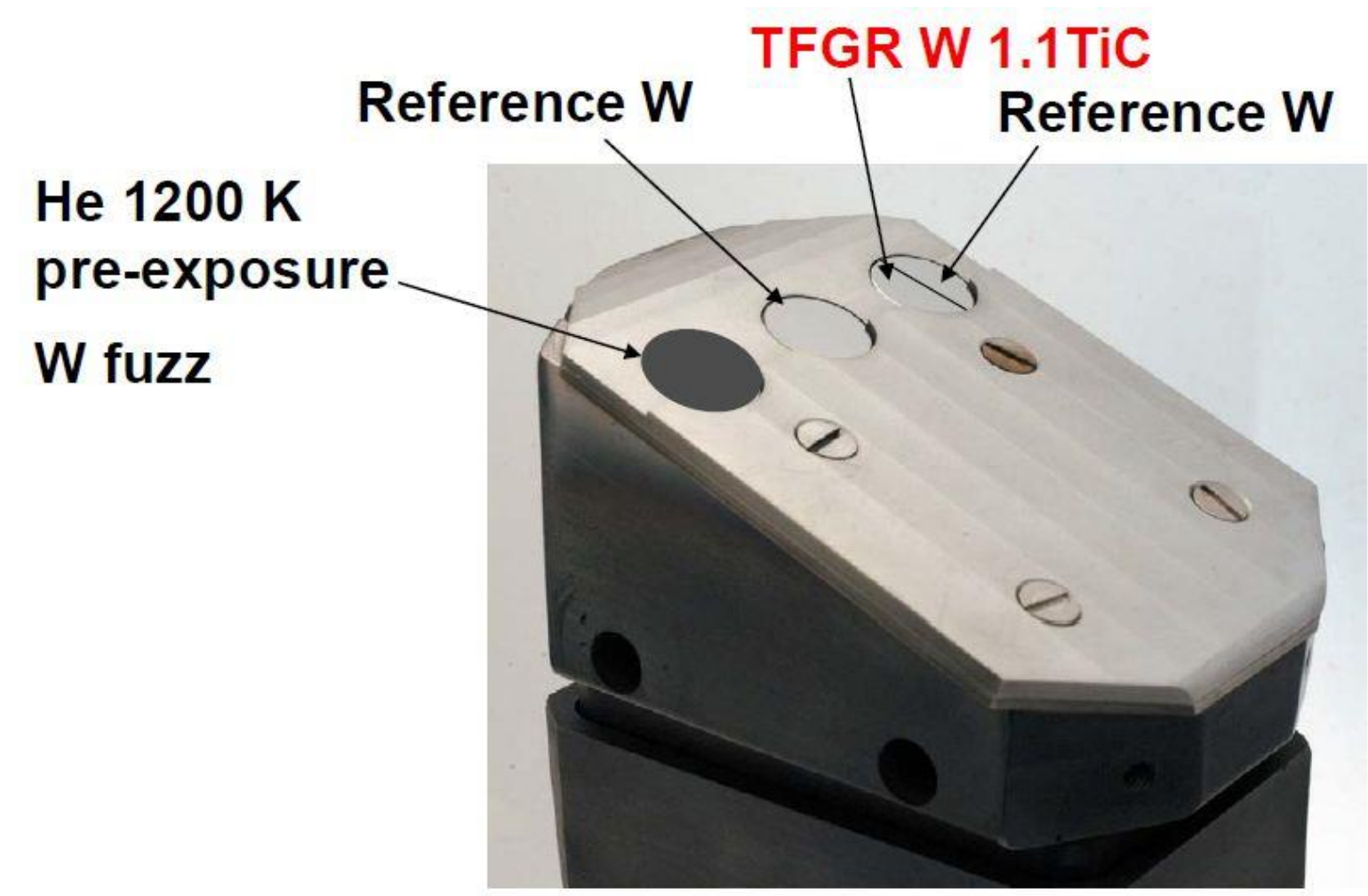


Figure 2: one column
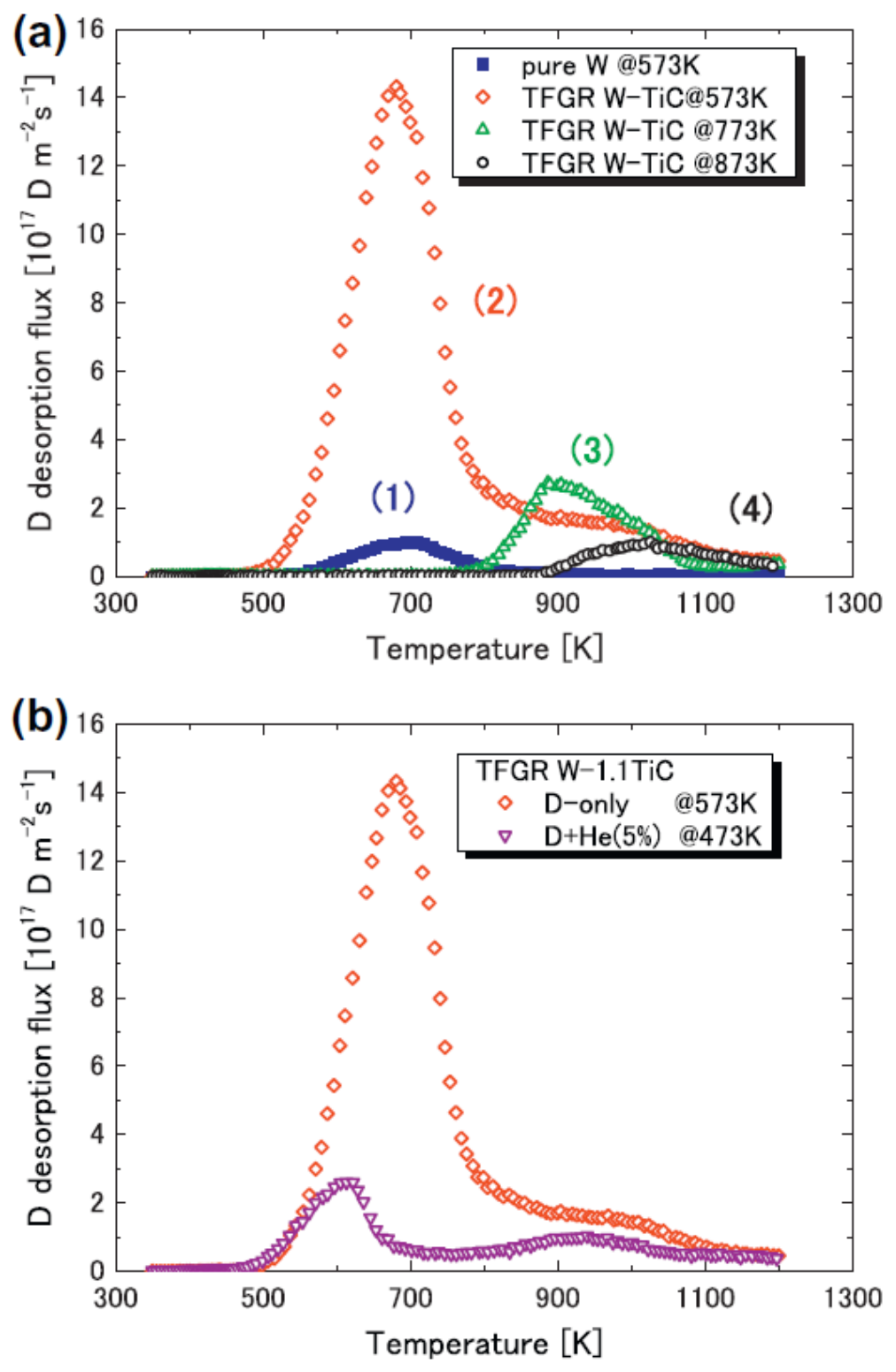
Figure 3: one column

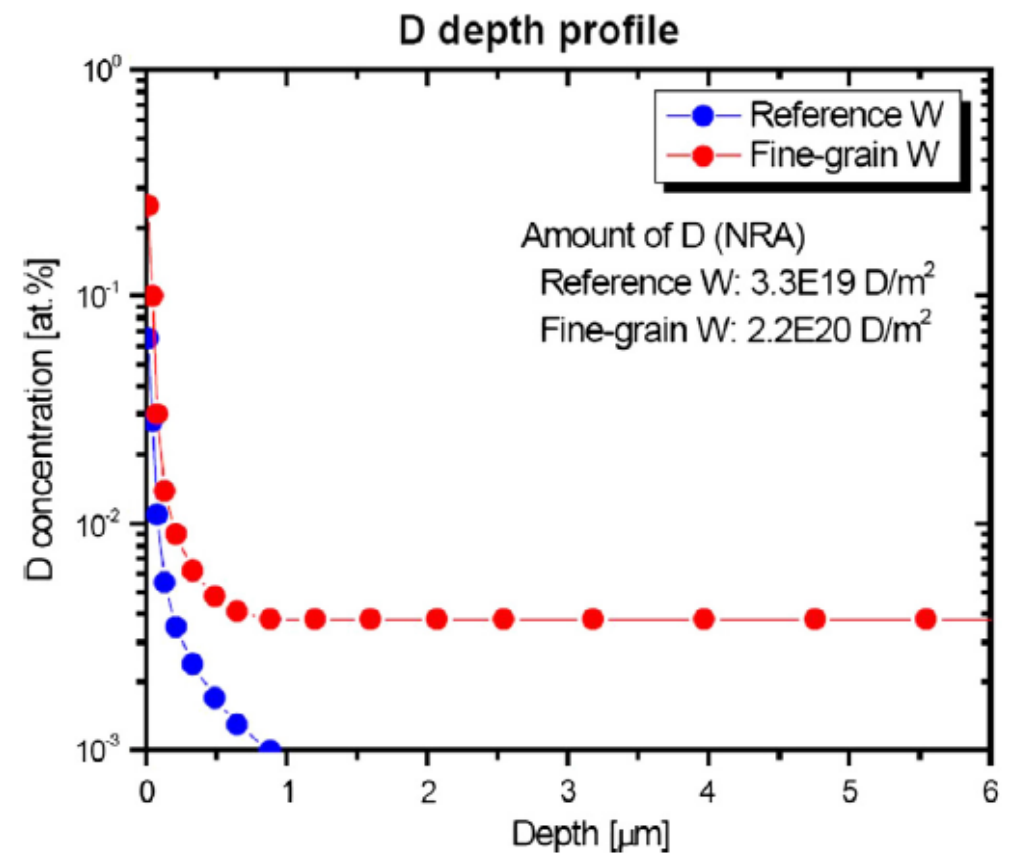


Figure 4: one column

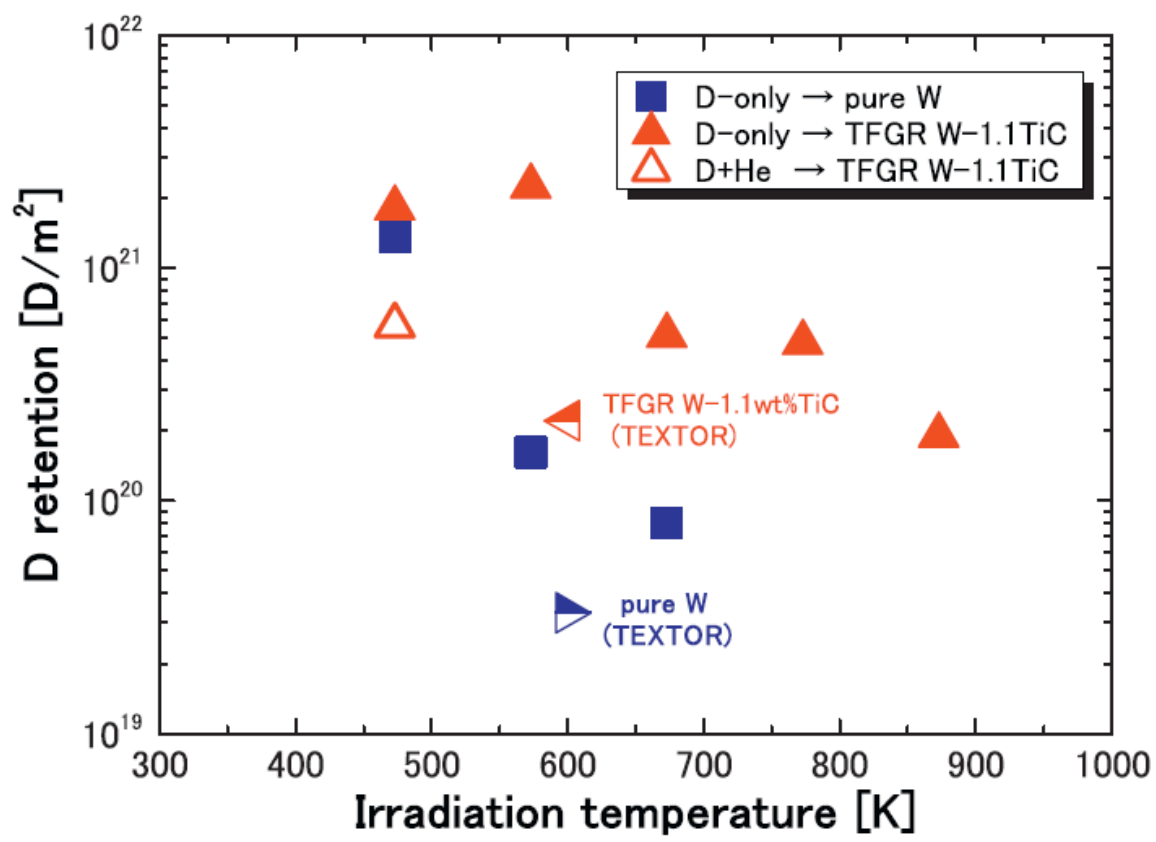

